\title{
A APLICAÇÃO DE PADRÕES COLONIAIS PELA CORTE EUROPEIA: UMA ANÁLISE DO CASO ARMANI DA SILVA VS. REINO UNIDO
}

\author{
Marina de Almeida Rosa ${ }^{1}$
}

\section{Resumo}

Instituída na Guerra Fria, a Corte Europeia de Direitos Humanos é o tribunal internacional voltado à proteção dos direitos humanos daqueles indivíduos que se encontram sob a jurisdição de um Estado europeu que tenha ratificado a Convenção Europeia de Direitos Humanos e reconhecido a competência do tribunal. No seio da Corte Europeia foi implementada em 1976, a doutrina da margem de interpretação, mecanismo interpretativo que confere aos Estados a discricionariedade de resolver assuntos que seriam exclusivamente de sua competência, como a segurança nacional. Desta forma, este trabalho tem por intuito examinar, através do método indutivo e do estudo de caso, em que medida a aplicação da doutrina da margem de apreciação remonta à aplicação de um pressuposto colonial. Isto porque, a doutrina da margem de apreciação é utilizada, na maioria dos casos, quando a vítima é migrante, isto é, quando se trata de um dos indivíduos subjulgados pela modernidade, e exime a responsabilidade internacional do Estado pelas violações aos direitos humano, como no caso do homicídio do brasileiro Jean Charles de Menezes (Caso Armani da Silva Vs. United Kingdom).

Palavras-chave: Margem de Apreciação; Direitos Humanos; Colonialismo; Migrantes.

\begin{abstract}
Instituted in Cold War, the European Court of Human Rights is the international court for the protection of the human rights of those individuals who are under the jurisdiction of an European State which has ratified the European Convention of Human Rights and recognized the competence of the Court. Within the European Court was implemented in 1976 the margin of appreciation doctrine, interpretative mechanism that confers to the State he discretion to resolve matters that would be

${ }^{1}$ Advogada. Professora de Direito Internacional e de Regimes Internacionais nos cursos de Graduação em Direito e em Relações Internacionais do UniRitter. Mestranda do Programa de Pós-Graduação em Direito da Universidade do Vale do Rio dos Sinos (UNISINOS) - Bolsista CAPES/PROEX. Possui Graduação em Direito pela Faculdade de Direito da Fundação Escola Superior do Ministério Público (2015) e pos-gradução em Direito Internacional Público, Privado e Direito da Integração pela Universidade Federal do Rio Grande do Sul (2016).
\end{abstract}


exclusively its competence, like the national security. Thus, this paper intended to examine, through inductive method and case study, the extent to which the application of the margin of appreciation doctrine goes back to the application of colonial assumption. This is because the margin of appreciation is used, in most cases, when the victim is a migrant, this is, when it comes to one of individual subjugated by modernity, and exempts the State's international responsibility for human rights violations, as in the case of the homicide of Brazilian Jean Charles de Menezes (Case of Armani da Silva Vs. United Kingdom).

Keywords: Margin of Appreciation; Human Rights; Colonialism; Migrants.

\section{INTRODUÇÃO}

A modernidade instaurou um padrão hierárquico de ser e saber que gradualmente classificava seres humanos entre aqueles que possuíam e aqueles que não possuíam direitos. Do primeiro grupo faziam parte aqueles considerados racionais, o homem, europeu, heterossexual, branco e proprietário, sendo que esse era o considerado humano; todo o restante da humanidade fazia parte do outro grupo, e, não sendo racionais, não eram sujeitos de direitos. Essa hierarquização de seres humanos implicou, ao fim e ao cabo, em um conceito de direitos humanos fundado, primordialmente, na garantia de direitos individuais e permitindo graves violações aos direitos daqueles oprimidos e dominados.

Deste modo, em um primeiro momento, os direitos humanos não se voltavam a todos, contribuindo à legitimação da modernidade e sendo manipulados pelos poderes hegemônicos. Entretanto, paulatinamente, o seu discurso vai tornando-se o discurso do oprimido, e, a partir dele, aqueles historicamente dominados passaram a exigir o reconhecimento de seus direitos mais básicos. Embora a pretensa universalização dos direitos humanos não correspondesse, a priori, à realidade de reconhecimento dos mesmos, ela fomentou a instituição de organismos internacionais e regionais voltados a 
essas garantias, como aquele instituído na Europa. O Sistema Regional Europeu, voltado à garantia de direitos individuais e dos padrões liberais de democracia, foi o primeiro a nível local a criar instâncias judiciais internacionais aptas a sancionar violações a essas garantias.

Considerando que cada vez mais os grupos vulneráveis têm figurado como vítima perante a Corte Europeia, a qual, ao invés de conferir uma interpretação progressista à Convenção Europeia de Direitos Humanos - em conformidade com o princípio pro personae-, concede aos Estados ampla margem de discricionariedade para, internamente, interpretar o texto convencional e restringir os direitos desses grupos, sem que isso, contudo, configure a sua responsabilidade internacional. Nesse sentido o presente trabalho busca analisar, através da aplicação do método indutivo e do estudo de caso, em que medida a aplicação da doutrina da margem de apreciação, pela Corte Europeia de Direitos Humanos, remonta à aplicação de um pressuposto colonial.

Parte-se da premissa de que a aplicação da doutrina da margem de apreciação implica em uma discriminação indireta e reafirma a complacência da ordem internacional com violações seletivas de direitos humanos, uma vez que a admissão desse parâmetro hermenêutico por parte do Tribunal implica na denegação de justiça àqueles que se encontram em uma condição de vulnerabilidade, e que representam os indivíduos a quem a colonialidade nega a categoria de ser humano. Para tanto, analisar-se-ão a fundamentação colonial dos direitos humanos e as suas implicações na instituição de organismos regionais de proteção desses direitos, particularmente, o Sistema Europeu de Proteção dos Direitos Humanos. Em seguida, examinar-se-á a instituição desse sistema, suas bases normativas e organismos. Por fim, proceder-se-á ao exame do caso referente ao homicídio do brasileiro Jean Charles de Menezes (Caso 
Armani da Silva) e das consequências da aplicação da doutrina da margem de apreciação ao caso.

\section{AS BASES DA PROTEÇÃO INTERNACIONAL DOS DIREITOS HUMANOS}

O conceito de sujeito de direitos e de "direitos humanos" introduzido pela modernidade pauta-se em uma hierarquização dos seres humanos, a partir de um discurso excludente com base no argumento de que podem exercer os seus direitos aqueles considerados racionais. Tal característica não impede, contudo, a sua exportação aos tratados internacionais de direitos humanos que se pretendiam universais e àqueles ditos regionais. Assim, examinar-se-á a fundamentação dos direitos humanos da modernidade e a instituição de um sistema regional de proteção de direitos humanos calcado nesses parâmetros: o Sistema Europeu de Proteção dos Direitos Humanos.

\subsection{A FUNDAMENTAÇÃO COLONIAL DOS DIREITOS HUMANOS}

Com o advento da modernidade, a partir do "descobrimento da América" iniciou-se um processo civilizatório em que a sociedade europeia, com aporte em discursos de evangelização e civilização, estabeleceu-se como centro do que veio a ser denominado de mundo moderno-colonial (LANDER,

2005, p. 11). A modernidade trouxe consigo a colonialidade, um padrão hierárquico de poder e de saber que mantém, nos planos ideológico-discursivo e das relações intersubjetivas, a dominação dos povos do Sul global (QUIJANO, 2005, p. 110). Isso somente é possível porque a partir de 1492, ano considerado 
por Dussel como o marco constitutivo da modernidade, a Europa estabeleceu a si mesma como centro e o fim da história e as demais culturas como sua periferia, iniciando um "mito" de modernidade (DUSSEL, 1994, p. 21).

A dominação europeia não interferiu apenas na integridade e na igualdade dos povos do Sul, mas transcendeu-se, no plano epistemológico, a um "discurso sobrepujante" (MIGNOLO, 2003, p. 49) que impôs a cosmovisão europeia como universal. A partir desse paradigma, as formas europeias de compreensão do mundo transformaram-se nas únicas formas válidas, objetivas e universais aplicáveis a qualquer realidade, em "proposições normativas que definem o dever ser para todos os povos do planeta", como observa Lander (2005, p. 10). Assim, as definições jurídicas e doutrinárias europeias passaram a ser implementas como único conhecimento válido, científico e útil.

Nesse sentido, Mignolo (2003, p. 7) sinala que embora a "revolução epistemológica" provocada pela modernidade tenha seu epicentro na Europa, a mesma irá influenciar todo o mundo através do racismo ontológico que fundamenta as concepções renascentistas de humanidade e de "homem", de sujeito de direitos, as quais serão utilizadas para medir, classificar, julgar e avaliar os seres humanos e, ao mesmo tempo, legitimar a suposta superioridade européia (MIGNOLO, 2003, p. 7). Logo, os valores hegemônicos sustentados pela colonialidade passam a influenciar não só as formas de ser e pensar, como também as regulamentações locais (QUIJANO, 2005, p. 11). Consequentemente, o conceito de direitos humanos, não passou desapercebido pelo discurso dominante.

Os critérios de hierarquização entre os seres humanos propostos pela modernidade estarão diretamente relacionados ao sujeito de direitos e ao embrião do discurso dos direitos humanos. A estrutura colonial de poder, que opera a partir do racismo e do patriarcado (MIGNOLO, 2008, p. 11), 
implementa um discurso de classificação dos seres humanos, de maneira que ser pessoa torna-se irrelevante, já que a "humanidade" é relativizada para reconhecer somente como humano aqueles admitidos pela modernidade. Dentre os critérios de hierarquização, a raça - fundamentada nas diferenças biológicas entre europeus e dominados, colonizador e colonizado - torna-se meio para outorgar legitimidade às relações de dominação instauradas pela colonialidade; aliado à raça, o critério intersexual, anterior à modernidade, também será utilizado para classificar a população mundial (QUIJANO, 2005, p. 117-118). Portanto, conquanto o conceito de "direitos humanos" pressuponha uma categoria de humano que seja universalmente aceita, esse mesmo conceito deixa de fora uma significativa parcela da população mundial (MIGNOLO, 2013, p. 44).

A classificação proposta pela modernidade remonta ao humanismo, dos séculos XV e XVI, com a introdução de um conceito de "homem" que paulatinamente viu-se atrelado ao "ser ocidental" e ser "cristão" (QUIJANO, 2013, p. 46-47), excluindo desse conceito aqueles que não eram homens, ocidentais, brancos e cristãos. Tampouco a Renascença europeia proporcionou um reconhecimento extensivo de "humano", com fundamento no direito natural - que reconhece direitos absolutos e eternos, outorgados por uma ordem divina (DOUZINAS, 2000, p. 23, 28-30, 50) -, a sua secularidade reconhecia que o fundamento da natureza humana do homem que justificaria a concessão de direitos subjetivos seria aquilo que distingue os seres humanos dos animais, ou seja, a razão.

Para Locke, o direito natural assegurou ao indivíduo princípios “simplesmente pela virtude do ser enquanto pessoa" (DOUZINAS, 2000, p. 8182) e esses direitos inatos restringiram-se à propriedade, à liberdade e à vida. Ocorre que segundo Locke, o Estado de Natureza, que permitia que os indivíduos fossem sujeitos daqueles direitos, decorreria exclusivamente do 
reconhecimento da razão (LOCKE, s/a, p. 36). Esse Estado de Natureza lockiano, portanto, não apenas restringiria direitos àqueles dotados de razão, como também reconhecia a possibilidade de discriminação e subordinação nas relações privadas, e que por um motivo nobre, ou pela ruptura da razão, um indivíduo fosse punido, ou submetido ao poder de outrem (LOCKE, s/a, p. 3639). Ou seja, o conceito e reconhecimento de humano de Locke também implicará na exclusão daqueles não tidos como racionais.

A relação intrínseca proposta pela modernidade entre a racionalidade e o exercício de direitos será também ressaltada por Kant, que reconhece o ser racional como fim em si mesmo ao afirmar que "[s]ó um ser racional tem capacidade de agir segundo a representação das leis, isto é, segundo princípio, ou: só ele tem uma vontade." (KANT, 2009, p. 47), sendo essa última "a faculdade de escolher só aquilo que a razão, independentemente da inclinação, reconhece como praticamente necessário [...]." (KANT, 2009, p. 47). Observa-se, assim, que Kant segue a premissa cartesiana de fundamentar o reconhecimento do sujeito de direitos em princípios estritamente racionais, de modo que os direitos humanos existiriam para concretizar as diferentes capacidades do ser humano. Há, deste modo, uma "conversão" do direito natural, que deixa de ter o seu fundamento no divino, para uma "a racionalidade humana, tornando-se subjetivo e racional" (KANT, 2009, p. 64).

Em outros termos, com base em uma concepção filosófica clássica, os direitos humanos referir-se-iam aos direitos natos, de maneira que eram devidos igual e naturalmente a todos pela sua condição humana, a qual deixa de estar vinculada à vontade divina e passa ser atrelada à razão dos seres humanos (DOUZINAS, 2000, p. 44, 49-53, 57,58). Deste modo, o pensamento moderno reconhece que “[p]rimeiro: todos têm direitos inalienáveis que decorrem de sua natureza humana; segundo: a racionalidade é o que nos define como humanos." (BRAGATO, 2016, p. 1808). Porém, corroborando a lógica de 
hierarquização da colonialidade, enquanto esse discurso reconhecia direitos a certos indivíduos, permitia que outros fossem escravizados, discriminados, violentados e torturados (DOUZINAS, 2000, p. 81-82). Foi sob esse fundamento que os textos considerados precursores dos direitos humanos pela historiografia clássica, como a Declaração de Independência dos Estados Unidos da América e a Declaração Francesa dos Direitos do Homem e do Cidadão, definiram direitos humanos (MIGNOLO, 2013, p. 44), não os garantindo a todos.

Com efeito, Galindo (2013, p. 11) adverte que, apesar do potencial emancipatório, a linguagem dos direitos humanos tem sido manipulada pelos poderes hegemônicos, sendo necessário tomar consciência do potencial opressivo de sua universalidade. Nesse sentido, há de se observar que embora Declaração Universal de Direitos Humanos, aprovada pela Assembleia Gera das Nações Unidas em 1948, tenha a aspiração de conferir a igualdade a todos os seres humanos, reafirma o reconhecimento da razão e da consciência como pressupostos dos seres humanos, e, como afirma Comparato (2015, p. 238), é omissa em relação aos abusos ocorridos na União Soviética e aos perpetrados pelas potenciais ocidentais.

De toda a sorte, a relevância da Declaração no plano universal é notória, pois em decorrência dela o direito internacional dos direitos humanos emerge como doutrina voltado a combater a violação aos direitos de grupos de vulneráveis, utilizando-se, para tanto, de um sistema universal (haja vista que a Declaração fomenta os tratados do Sistema das Nações Unidas) de proteção de direitos humanos que será complementado por sistemas regionais, os quais observem as particularidades das regiões nas quais estão inseridos. 


\subsection{A REGIONLIZAÇÃO DOS DIREITOS HUMANOS E O SISTEMA EUROPEU DE PROTEÇÃO DOS DIREITOS HUMANOS}

Em 1949, após as atrocidades vivenciadas na II Guerra Mundial, um "movimento europeu", formado por Bélgica, Dinamarca, França, Holanda, Irlanda, Itália, Luxemburgo, Noruega, Reino Unido e Suécia, instituíra um conselho voltado à proteção dos valores democráticos ocidentais e dos direitos humanos (GREER, 2010, p. 454-455; COUNCIL OF EUROPE, 1949, art. 3). Inspirado pela Declaração Universal dos Direitos Humanos, esse novo "Conselho da Europa" estabeleceu as bases para um futuro tratado de proteção de direitos humanos, voltado à garantia de direitos civis e políticos, que criou um tribunal regional voltado a protegê-los, a Corte Europeia de Direitos Humanos (CANÇADO TRINDADE, 2003, p. 119-120).

Ocorre que a criação desse Sistema Europeu de Direitos Humanos inseriu-se em um contexto maior de cooperação europeia para consolidar-se no período da Guerra Fria, fortalecer as suas economias e, sobretudo, estabelecer um contraponto ao regime soviético, ao pregar que os direitos humanos e a democracia eram garantidos na e pela Europa/regime capitalista, enquanto que o mesmo não seria promovido na zona de influência soviética (CARVALHO RAMOS, 2012, p. 161). Desta feita, a internacionalização dos direitos humanos na Europa tornou-se meio de estabelecer diferenças entre o sistema capitalista e o sistema socialista, e de conferir forças aos partidos liberais que disputavam eleições internas contra partidos socialistas ou comunistas (CARVALHO RAMOS, 2012, p. 162, 164), sendo aperfeiçoado para preservar a soberania dos Estados.

A Convenção Europeia de Direitos Humanos foi o instrumento normativo escolhido pelo Conselho da Europa para instituir o sistema regional 
de proteção dos direitos humanos. Elaborada em 1950, a redação original da Convenção Europeia para a Proteção dos Direitos Humanos e das Liberdades Fundamentais volta-se à proteção exclusivamente de direitos civis e políticos (CASTILLO DAUDI, 2006, p. 112), o que para Comparato (2015, p. 281-282) constitui um retrocesso se comparada à Declaração Universal dos Direitos Humanos, pois somente dez anos depois da instituição da Convenção é que o Sistema Europeu reconhece direitos econômicos, sociais e culturais (Carta Social Europeia) e apenas na década de 1980 é que o direito à igualdade de possibilidades é inserido no texto convencional. $O$ escopo de proteção da Convenção também é visto com cautela por Cançado Trindade (2003, p. 123), em vista da priorização da garantia dos direitos individuais.

Portanto, ao resgatar o espírito da Declaração Universal de Direitos Humanos, o Conselho da Europa parte do pressuposto de que "direitos e democracia são partes integrantes do patrimônio jurídico dos Estados Europeus Ocidentais." (CARVALHO RAMOS, 2012, p. 181),o que reafirma a historiografia clássica dos direitos humanos, e vai ao encontro do conceito moderno de direitos. Nesse sentido, embora o Sistema Europeu possa ter evoluído, de modo a buscar ampliar a proteção de direitos e indivíduos sob a tutela dos Estados Europeus, o mesmo nasce com o espírito e fundamento jurídico da modernidade. Não se refuta, entretanto, que o Sistema inova ao instituir organismos judiciais independentes no plano internacional para julgar violações a esses direitos: a Comissão Europeia de Direitos Humanos, o Comitê dos Ministros do Conselho de Europa e a Corte Europeia de Direitos Humanos (MERRILLS, 1990, p. 1; MENEZES, 2013, p. 185). Desta forma, surge com uma vocação eminentemente jurisdicional que experimentou diversas modificações ao longo de sua história (LÓPEZ GUERRA, 2014, p. 168).

A redação original da Convenção Europeia institui dois órgãos de supervisão dos direitos humanos no continente: a Comissão e a Corte Europeia 
de Direitos Humanos. A Comissão recebia denúncias de indivíduos e/ou grupos particulares quanto à violação de algum direito consagrado no referido tratado e procedia ao exame de sua admissibilidade, além de realizar conciliações, ordenar medidas preliminares de proteção dos direitos humanos e, eventualmente, encaminhar casos à Corte ou ao Comitê de Ministros (CANÇADO TRINDADE, 2003, p. 124-125). Deste modo, exercia um papel quasi judicial, já que os casos apenas poderiam chegar à Corte Europeia após o seu prévio juízo de admissibilidade e a compreensão da existência da violação (CARVALHO RAMOS, 2012, p. 166; MERRILLS, 1990, p. 02).

O procedimento instaurado pela Convenção Europeia compreendia a apresentação de uma demanda interestatal ou individual, ambas perante a Comissão, que após a admissibilidade e a tentativa de conciliação, deliberava quanto à responsabilidade internacional do Estado, e encaminhava, se entendesse por violado o tratado, o caso à Corte Europeia de Direitos Humanos (CARVALHO RAMOS, 2012, p. 165-166). Por sua vez, o Conselho de Ministros possuía competência residual para examinar um caso, se a Corte ou a Comissão não fossem instadas (CARVALHO RAMOS, 2012, p. 169), enquanto que a Corte Europeia tinha como função essencial proferir sentenças sobre eventual responsabilidade internacional dos estados-parte da Convenção Europeia a ela submetidos por esses estados ou pela Comissão (CANÇADO TRINDADE, 2003, p. 126).

As funções dos órgãos e o sistema de petições foram alterados após a instituição do Protocolo $n^{\circ} 11$ de 01 de novembro de 1998. Com as inovações propostas, a Comissão Europeia de Direitos Humanos foi extinta, de modo que os indivíduos, grupos de indivíduos ou organizações não-governamentais sob a jurisdição dos Estados-parte da Convenção Europeia, bem como esses Estados, passaram a ter legitimidade ativa para peticionar diretamente à Corte Europeia (CARVALHO RAMOS, 2012, p. 173-174; CANÇADO TRINDADE, 2003, p. 141- 
142; GREER, 2010, p. 462-463; TOMUSCHAT, 2008, p. 240-241), sendo reconhecido o locus standi aos indivíduos no direito internacional. As alterações não ficaram adstritas à Comissão e à Corte, mas também as atividades do Conselho de Ministros foram modificadas, conferindo-se competência exclusiva à Corte Europeia para decidir sobre a responsabilidade internacional de um Estado pela violação da Convenção Europeia de Direitos Humanos (CANÇADO TRINDADE, 2002, p. 140).

Havendo o reconhecimento da responsabilidade internacional estatal, será necessário conceder à parte lesada uma razoável reparação do direito violado (TOMUSCHAT, 2008, p 253). A sentença proferida pela Corte Europeia é, portanto, definitiva e vinculante e deve ser acatada pelo Estado demandado. Todavia, são os Estados que "decidem as vias concretas mediante as quais se produz esse acatamento em seu ordenamento jurídico" (LÓPEZ GUERRA, 2014, p. 174, Tradução nossa). ${ }^{2}$

No exercício de suas faculdades, o Sistema Europeu, sobretudo, a Corte Europeia a partir de 1998, tem contribuído à proteção dos direitos humanos na Europa, seja pelo reconhecimento da capacidade processual aos indivíduos, seja pela robusta jurisprudência firmada. Entretanto, a atuação do tribunal e do Sistema tem sido limitada pela aplicação da doutrina da "margem de apreciação" que designa que os Estados possuem um espaço de manobra para que exerçam as suas funções (COUNCIL OF EUROPE, s/d) o que permite que os mesmos adotem as medidas julgadas adequadas para interpretar e proteger os direitos consagrados na Convenção Europeia, uma vez que estariam em melhor posição para definir o conteúdo e limites dos mesmos (EUROPEAN COURT OF HUMAN RIGHTS, 1976, p. 17; EUROPEAN COURT OF HUMAN RIGHTS, 2016, p. 63).

${ }^{2}$ No original: "decidan las vías concretas mediante las que se produce ese acatamiento en su ordenamiento interno". 


\section{CASO ARMANI DA SILVA VS. UNITED KINGDOM E A DOUTRINA DA MARGEM DE APRECIAÇÃO}

O Sistema Europeu de Proteção dos Direitos Humanos fundamenta-se na garantia de direitos individuais, servindo não só como mecanismo de proteção desses direitos, como também de afirmação das democracias ocidentes. Em 2016, a Corte Europeia, instância supranacional a quem compete decidir pela responsabilidade internacional dos Estados pela violação da Convenção Europeia de Direitos Humanos, examinou o caso do brasileiro Jean Charles de Menezes, morto pela polícia britânica ao ser confundido com terroristas. No caso, o tribunal aplicou a doutrina da margem de apreciação, não reconhecendo a responsabilidade internacional do Reino Unido. Diante disso, examina-se o caso Armani da Silva, o contexto no qual se insere e a relação entre a exegese da margem de apreciação e a colonialidade.

\subsection{AS VIOLAÇÕES DE DIREITOS DE VULNERÁVEIS EM NOME DA SEGURANÇA NACIONAL}

Em 7 de junho de 2005, a cidade de Londres sofreu quatro atentados terroristas em seus transportes públicos, que resultaram na morte de cinquenta e seis pessoas e em vários feridos. Devido a essas circunstâncias, o Metropolitan Police Service iniciou uma força tarefa para investigar a identidade de pessoas que pudessem estar vinculadas ao atentado, uma vez constatado que um novo ataque poderia ocorrer. Diante disso, o nível de ameaça representado pelo Reino Unido contra o terrorismo internacional foi aumentado do nível 3 para o nível 1. Exatamente duas semanas depois, em 21 de junho de 2005, quatro explosivos foram encontrados nos metrôs, iniciando-se uma operação para 
encontrar os responsáveis, sendo identificados dois suspeitos que viveriam na Scotia Road, Londres (EUROPEAN COURT OF HUMAN RIGHTS, 2016).

No dia seguinte, foi montada uma operação de vigilância no local onde os suspeitos estariam vivendo, a qual foi transferida para a Estação do Metrô de Nightingale Lane, pois havia indícios de que os mesmos lá estavam, e, por serem considerado perigosos, os policiais londrinos estavam fortemente armados. Paralelamente à organização contra os suspeitos, o brasileiro Jean Charles de Menezes, que viva na Scotia Road, deixou sua residência em direção ao mesmo metrô em que a força tarefa londrina se encontrava. Devido a sua aparência e a possível semelhança com um dos suspeitos, os policiais londrinos que faziam a vigilância sugeriram que o mesmo fosse parado para que prestasse informações. Isso, contudo, não ocorreu, e Jean Charles foi seguido pelo Metropolitan Police Service (EUROPEAN COURT OF HUMAN RIGHTS, 2016).

Sem confirmar a identidade de Jean Charles como suspeito, os agentes policiais o seguiram dentro do metro, o imobilizaram e disparam várias vezes contra ele, matando-o (EUROPEAN COURT OF HUMAN RIGHTS, 2016, pára 37). Todavia, poucos dias após o homicídio, o Reino Unido constatou que o brasileiro não estava envolvido na tentativa de ataque terrorista (EUROPEAN COURT OF HUMAN RIGHTS, 2016, pára 38). Os processos administrativo e judicial, esse último impetrado pela família de Jean Charles, não lograram responsabilizar nenhum agente estatal do Reino Unido pelo homicídio - e tampouco houve a proteção diplomática por parte do Brasil-, uma vez que os agentes haviam agido sob a margem de apreciação estatal para coibir práticas de terrorismo. Diante disso, a prima de Jean Charles acudiu à Corte Europeia de Direitos Humanos, sustentando a violação, pelo Reino Unido, ao direito à vida e aos procedimentos judiciais (EUROPEAN COURT OF HUMAN RIGHTS, 2016, pára. 12). O Tribunal, porém, não responsabilizou o Estado pelo 
homicídio do brasileiro e pela ausência de devida investigação, ao argumento de que a discricionariedade do Reino Unido para lidar com questões referentes a sua segurança não configurava violação à Convenção Europeia.

A conjuntura internacional em que se insere o homicídio de Jean Charles de Menezes remonta a guerra ao terror iniciada a partir de 11 de setembro de 2001. A respeito desse contexto, vale recordar que, ironicamente, a Assembleia Geral das Nações Unidas, em 1998, declarou que o ano de 2001 seria "Ano das Nações Unidas para o Diálogo entre Civilizações", a partir da reafirmação dos propósitos e princípios da Carta das Nações Unidas, de um esforço coletivo para o fortalecimento da paz e da segurança internacional pelos Estados (UNITED NATIONS, 1998). Nesse mesmo ano, porém, dois aviões comerciais, sequestros pela Al-Qaeda, atingiram um dos símbolos máximos da influência e poder ocidental: as torres gêmeas do World Trade Center em Nova Iorque. A partir dos atentados, a guerra ao terror instaurou o foco de tensão internacional mais perigoso desde o início do Século XXI (VISENTINI, 2004, p. 42-43), contrariando a ideia de que o referido ano e os subsequentes poderiam ser anos de diálogo entre os povos.

Para Habermas, os atentados de 2001 não provocaram apenas as destruições das torres, mas, em verdade, do ícone e da imagem da "nação americana" que reconhecia no edifício o símbolo do poder econômico e das aspirações ocidentais (HABERMAS, 3006, p. 12). Além disso, para ele, o terrorismo teria tornado a estimativa do risco e do conhecimento do inimigo impossíveis, o que faria com que os Estados ameaçados reagissem a esses riscos indefinidos podendo "[...] eventualmente exceder-se - e devido à precariedade das informações dos serviços secretos, sem poder saber se as suas reações são excessivas." (HABERMAS, 2006, p. 14). 
Com sustento nesse argumento e diante do cenário de terror instaurado após os atentados, os Estados passaram a expedir leis antiterror que restringiam direitos individuais em "prol" de proteção da coletividade, deixando de observar, inclusive, as suas obrigações internacionais (SQUEFF, 2016, p. 173). Nota-se, no entanto, que a expedição de legislações antiterror não se restringiu aos Estados Unidos, onde ocorridos os atentados, mas espalhou-se pelos demais Estados hegemônicos, como é o caso do Reino Unido. A partir da modificação de sua legislação doméstica, através da promulgação do Anti Terrorism Crime and Secutiry Act de 2001, o Reino Unido estabeleceu a possibilidade de realizar prisões arbitrárias, deportar indivíduos e restringir direitos e garantias em casos de ameaça à segurança, como feito em relação a Jean Charles de Menezes (SQUEFF, 2016, p. 180).

No entanto, somente a ingenuidade permitiria convergir com Habermas, pois a instituição de legislações amplas, que conferem irrestrita margem de discricionariedade aos Estados, aliada à sofisticação dos serviços de segurança, como a MI6 ou a CIA, demonstra o interesse objetivo de conferir uma exceção à aplicação e resguardo de certos direitos a determinados indivíduos, sem que isso soe à comunidade internacional como violação aos direitos humanos. Nesse sentido, Pereira (2014, p. 58) sustenta que o discurso de "projeto inacabado" dos direitos humanos preconizado por Habermas embasado em Kant, "não passa de uma quimérica ideologia vã", que ao idealizá-los não considera as necessárias mudanças do mundo real e permite a instituição de mecanismos de exceção a serem aplicados aos indivíduos que "condena a ação dos excluídos que se recusam a utilizar as regras preestabelecidas para lutar contra sua exclusão.".

Ademais, a criação de um inimigo invisível possibilita um discurso diário de segurança, que fundamenta fiscalizações, investigações e eventualmente torturas daqueles que podem significar alguma ameaça 
(PEREIRA, 2014, p. 66). Deste modo, em nome da democracia liberal e da manutenção das "liberdades fundamentais" do ser humano é possível subverter toda a estrutura dos direitos humanos (PEREIRA, 2014, p. 67) permitindo que supostos inimigos sejam aniquilados, mesmo que não demonstrem qualquer perigo, como fora Jean Charles de Menezes. Isso porque, com um discurso de direitos humanos baseado na proteção da segurança da coletividade, os Estados conseguem eliminar o “indesejado" (PEREIRA, 2014, p. 74-75), o outro. Para Anghie (2016, 120-123), o fundamento dessa "guerra ao terror" vai ao encontro do imperialismo e dos padrões impostos pela modernidade, uma vez que a partir de uma guerra justa, de um discurso civilizatório, já que o outro é incivilizado, fundamentam o uso da força.

Deste modo, ao invés do reconhecimento da própria responsabilidade dos Estados hegemônicos nos atos de terrorismo a partir de 11 de setembro e dos atentados subsequentes, o que ocorreu foi um choque de fundamentalismos, uma vez que o Ocidente legitima a repressão ao terrorismo a qualquer custo, sem considerar que os atentados podem estar relacionados à imposição dos padrões hegemônicos ao mundo, reforçando o "anseio do democrata colonizador" (PEREIRA, 2014, p. 60-62). Nessa guerra ao terror, aquele que mais sofre é o migrante que tenta reconstruir a sua vida no exterior (PEREIRA, 2014, p. 73).

Desta forma, a permissão de violação de direitos humanos em nome da segurança internacional e nacional, como ocorrido no caso de Jean Charles de Menezes, demonstra a contradição da tradição hegemônica dos direitos humanos, ou, em outros termos, o seu resgate, já que viabiliza que os direitos daqueles que não estão adequados ao estereótipo de "seguro", ou daqueles que contestem as imposições ocidentais, possam ser violados em nome de uma nova “ordem natural" que passa a ser a segurança internacional. A violação de direitos desses indivíduos decorre de uma seleção que está diretamente 
vinculada à inferiorização hierárquica da sua humanidade, no caso específico: não é ocidental, pode parecer perigoso e logo não tem direito a ter direitos, podendo o Estado utilizar-se de ampla discricionariedade.

\subsection{A APLICAÇÃO DA “MARGEM DE APRECIAÇÃO” E 0 CASO ARMANI DA SILVA COMO REAFIRMAÇÃO DA COLONIALIDADE}

A doutrina da margem de apreciação surge em um Sistema Europeu de Proteção de Direitos que se acreditava exemplar e homogêneo (CANÇADO TRINDADE, 1999, p. 124). Trata-se de um critério hermenêutico desenvolvido pela Corte Europeia de Direitos Humanos e que permite um âmbito de discricionariedade ou "espaço de manobra" dos Estados a respeito da forma como cumprem as obrigações decorrentes da Convenção Europeia, considerando as suas circunstâncias e condições particulares (GREER, 2010, p. 2). Para Carvalho Ramos, a referida doutrina "consiste na abstenção de análise, pela Corte EDH, de casos polêmicos de direitos humanos, permitindo que cada Estado do Conselho da Europa possa exercer uma 'margem de apreciação' sobre os contornos dos direitos protegidos." (CARVALHO RAMOS, 2012, p. 181).

Delmás-Marty e Izorche (2000, p. 753-780) indicam que a margem de apreciação permite que surjam diversas ordens e sistemas jurídicos, o que pode ser visto como uma contrariedade à necessária característica contra majoritária dos direitos humanos (CARVALHO RAMOS, 2012, p. 180). Todavia, a doutrina da margem de apreciação pode ser compreendida, também, como mecanismo que propicia e amplia o escopo da soberania estatal e da não interferência nos assuntos internos, já que excluem do exame do tribunal internacional questões que, embora, a priori, violem as obrigações internacionais do Estado, são 
tratadas como assuntos que devem ser resolvidos pela discricionariedade estatal. Ocorre que, a doutrina da soberania estatal implica na expulsão do "mundo não europeu" (ao excluir as sociedades não européias do âmbito de soberania e poder) e propicia o imperialismo (ANGHIE, 2016, p. 101-102), o que será observado quando da aplicação da doutrina da margem pela Corte Europeia de Direitos Humanos.

Inicialmente, o uso da margem de apreciação restringia-se ao exame do artigo 15 da Convenção Europeia (que possibilita a restrição de direitos em casos de guerra e de perigo público que ameacem os Estados, sem autorizar, contudo, a restrição do direito à vida). Todavia, a Corte Europeia passou a estendê-la aos outros direitos consagrados na Convenção (FEINGOLD, 1997, p. 94; RASILLA DEL MORAL, p. 613). Nesse sentido, o Tribunal consigna que as autoridades locais possuiriam uma melhor posição para opinar sobre as exigências morais e a necessidade para sancionar ou restringir um direito (EUROPEAN COURT OF HUMAN RIGHTS, 1976).

Seguindo essas premissas, a Corte aplicou a margem de apreciação ao caso Armani da Silva. Assim, afirmou que as ações da Scotland Yard não eram arbitrárias, e que, portanto, o Estado não estava obrigado a investigar e sancionar uma violação do direito à vida, se o seu poder judiciário compreendesse que a ação que gerou o homicídio enquadrava-se na margem de apreciação de ação estatal, como o argumento britânico justificava as ações com base na necessária proteção da segurança nacional.

Todavia, como assinala Carvalho Ramos (2012, p. 181), a aplicação da margem de apreciação a grupos minoritários - como era o caso do migrante Jean Charles de Menezes-, se converte em uma verdadeira denegação de justiça. Isso porque uma análise da jurisprudência da Corte Europeia permite concluir que na grande maioria dos casos de aplicação da referida doutrina, as vítimas 
são cidadãos não europeus. Ademais, o argumento de proteção da segurança nacional remonta os primórdios do direito internacional, a missão civilizadora (ANGHIE, 2016, p. 121), o qual surge com o intuito de subjulgar os povos, propiciar o comércio internacional e garantir a soberania dos impérios e estados europeus (BROWNLIE, 2008, p. 289-290). Ou seja, o próprio tribunal internacional permite que esses indivíduos sofram restrições de seus direitos pela presença de traços identitários e biológicos que lhe caracterizariam como "não ocidentais", e, portanto, como perigosos à comunidade européia e reafirma padrões coloniais. A conduta da Corte Europeia pode ser compreendida como uma prática de discriminação indireta ${ }^{3}$, que ocorre ainda que não se possa comprovar a intenção discriminatória, acarretando em um dano/prejuízo a um determinado grupo por suas características (RIOS, 2008, p. 89-90, 117).

Em outros termos, a decisão do tribunal no caso do brasileiro Jean Charles de Menezes parece, por vezes, retomar a retórica vazia do direito à igualdade preconizado pela modernidade. Se o reconhecimento à igualdade e à não discriminação alteram a concepção eurocêntrica de igualdade (BRAGATO; ADAMATTI, 2014, p. 91-108), a contrariedade desse por parte de um tribunal internacional de proteção desses direitos questiona o escopo de proteção dos mesmos e as bases modernas que fundamentam a gênese dessa Corte, na medida em que suas decisões hodiernamente convertem-se em novos erros e as supostas vítimas que nela buscam amparo em apenas mais um "tijolo" sob a margem de discricionariedade estatal.

\footnotetext{
${ }^{30}$ s direitos à igualdade e a não discriminação definem-se como verdadeira obrigação do Estado para com a comunidade internacional, permeando todo o corpus juris de tutela da pessoa humana. Trata-se do dever estatal de garantir, sem discriminação, o direito de todos aqueles indivíduos que se encontrem sob sua jurisdição. Essas garantias estão implícitas em toda a normativa internacional de proteção humana, a partir das quais decorrem todos os outros. (SHELTON, 2008, p. 15-39).
} 


\section{CONSIDERAÇÕES FINAIS}

A modernidade caracteriza-se pela implementação de um padrão hegemônico que transcende relações comerciais e que se consubstancia em um plano epistemológico a partir da hierarquização de seres humanos. A face oculta da modernidade, a colonialidade, permitiu que através de um fundamento de supremacia de indivíduos sobre os outros, a esses últimos fossem negados os seus direitos mais básicos. Nesse sentido, toda a construção da historiografia clássica dos direitos humanos possuí o mesmo fim: são discursos de racionalidade que conferem direitos a poucos indivíduos, considerados racionais, enquanto a outros simplesmente os nega, de modo que os valores hegemônicos passam a constar em todas as declarações de direitos.

As primeiras declarações internacionais de direitos humanos seguem essa mesma lógica: afirmam direitos individuais e se pretendem universais, sem, conduto, atentar para diferenças fundamentais entre cada uma das regiões, ou seja, presumem que todos vivem sob a mesma realidade e circunstâncias daquelas vividas pelos poderes hegemônicos. Invariavelmente, a modernidade afeta a Declaração Universal dos Direitos Humanos e outros tratados que a sucederam, como é o caso da Convenção Europeia de Direitos Humanos.

Nesse contexto, a Convenção Europeia surge com traços tipicamente coloniais, já que para além de buscar proteger os direitos humanos em um continente europeu devastado por duas guerras mundiais, procura firmar as democracias liberais em colapso e conferir a esses direitos uma titularidade quase que exclusiva da zona de influência capitalista, em face da socialista. Com fundamento nas liberdades individuais, o texto convencional europeu procura garantir direitos e, ao mesmo tempo, autonomia aos Estados. Sob essas 
premissas, portanto, é instituído o Sistema Europeu de Proteção dos Direitos Humanos.

Embora a atuação desse Sistema tenha contribuído à proteção dos direitos humanos não só no âmbito regional, como também na América e na África, pois serve de modelo aos sistemas regionais lá instaurados, a sua atuação tem sido limitada pelo resgate de parâmetros coloniais através da aplicação da doutrina da "margem de apreciação". No exame do caso Armani da Silva, é possível observar que o tribunal confere aos Estados a possibilidade de adotar a medida que julgue pertinente para interpretar a aplicabilidade e a proteção dos direitos consagrados na Convenção Europeia, o que permite que sejam violados direitos em face da proteção da coletividade.

Esse argumento de seguridade ganha força com os eventos de setembro de 2001 e os posteriores atentados terroristas ocorridos na Europa. Com base nesses fatos, os Estados passam a adotar legislações que contrariam a suas obrigações internacionais e que lhes facultam restringir direitos humanos daqueles que aparentem algum perigo. Desta forma, novamente, o discurso dos direitos humanos, nesse caso o direito humano à segurança da coletividade, dá espaço para que novas violações sejam perpetradas e admitidas em face de grupos minoritários, já que, na maioria dos casos, aqueles considerados perigosos, tal como fora Jean Charles de Menezes, não possuem quaisquer relações com os atentados terroristas, mas apenas não se enquadram no estereótipo europeu de "homem seguro".

Por outro lado, ao examinar um caso que envolve esse tipo de violação a Corte Europeia de Direitos Humano tem, com fulcro na aplicação da doutrina da margem de apreciação, sido complacente com as violações. Vale dizer que o tribunal admite a diferenciação e o reconhecimento de que certos indivíduos têm menos direitos do que outros por, simplesmente, não parecerem seguros. 
Tal posição, além de configurar uma discriminação indireta, autoriza a prática por uma instância que deveria buscar a proteção em igual condições de todos os indivíduos sob a jurisdição dos Estados europeus, permitindo que o discurso dos direitos humanos seja, novamente, utilizado e manipulado pelos poderes hegemônicos.

\section{REFERÊNCIAS}

ANGHIE, Antony. La evolución del derecho internacional: realidades coloniales y poscoloniales. In: ANGHIE, Antony; KOSKENNIEMI, Martti; ORFORD, Anne. Imperialismo y derecho internacional. Bogotá: Siglo del Hombre, 2016

BRAGATO, Fernanda Frizzo. Discursos desumanizantes e violação seletiva de direitos humanos sob a lógica da colonialidade. Quaestio Iuris. Vol. 09, n. 04. Rio de Janeiro, 2016, p. 1806-1823.

ADAMATTI, Bianka. Igualdade, não discriminação e direitos humanos: são legítimos os tratamentos diferenciados? Revista de Informação Legislativa. Ano 51 Número 204 out./dez. 2014, p. 91-108.

BROWNLIE, Ian. Principles of Public International Law. $7^{\text {th }}$ Ed. New York: Oxford University Press, 2008.

CANÇADO TRINDADE, Antônio Augusto. Tratado de direito internacional dos direitos humanos. Volume III. Porto Alegre: Sergio Antonio Fabris, 2003.

Tratado de direito internacional dos direitos humanos.

Volume II. Porto Alegre: Sergio Antonio Fabris, 1999.

CARVALHO RAMOS, André de. Processo Internacional de Direitos

Humanos. 2 ed. São Paulo: Saraiva, 2012.

CASTILLO DAUDÍ, Mireya. Derecho internacional de los derechos humanos. $2^{\mathrm{a}}$ Ed. Valencia: Tirant lo Blanch, 2006.

COMPARATO, Fábio Konder. A afirmação histórica dos direitos humanos. 9. Ed. São Paulo: Saraiva, 2015.

COUNCIL OF EUROPE. Statute of the Council of Europe. ETS No.001. London, 1949. 
The Margin of Appreciation. s/d. Disponível em:

<www.coe.int/t/dghl/cooperation/lisbonnetwork/themis/echr/paper2_en.as p\#P250_>. Acesso em 08 jun. 2017.

DELMAS-MARTY, Mireille; IZORCHE, Marie-Laure. Marge nationale d'appréciation et internationalisation du droit. Réflexions sur la validité formelle d'un droit commun pluraliste. Revue internationale de droit comparé. 2000. V. 52 N. 4, p. 753-780

DOUZINAS, Costas. The End of Human Rights. Portland: Hart Publishing, 2000.

DUSSEL, Enrique. 1492. El encubrimiento del Outro. Hacia el origen de "mito de la mordernidad". Colección Academia número uno. La Paz: Plural Editores, Facultad de Humanidades y Ciencias de la Educación - UMSA, 1994.

EUROPEAN COURT OF HUMAN RIGHTS. Case of Armani Da Silva v. United Kingdom Case. Application n.5878/08). Judgment of 30 march 2016.

Case of Handyside v. United Kingdom. Application n.

5493/72. Judgment of 12 june 1976.

FEINGOLD, Cora S. Doctrine of Margin of Appreciation and the European Convention on Human Rights. Notre Dame Law Review. V. 53. Issue 1 Article 6, 1997.

GALINDO, George Rodrigo Bandeira. A volta do terceiro mundo ao direito internacional. Boletim da Sociedade Brasileira de Direito Internacional. v $1 \mathrm{n}$ 119 -124. ago./dez. 2013

GREER, Steven. Europe. In: MOECKLI, Daniel (Org). International Human Rights Law. New York: Oxford University Press, 2010.

The interpretation of the european convention on human rights: universal principle or margin of appreciation?. UCL Human Rights Review. p. 1-14. Vol. 3, 2010

HABERMAS, Jürgen. O ocidente dividido. Tradução de Luciana Villas Bôas. Rio de Janeiro: Tempo Brasileiro, 2006.

KANT. Inmanuel. Fundamentação da merafísica dos costumes. Edições 70, 2009.

LANDER, Edgardo. Ciencias sociales: saberes coloniales y eurocéntrico. In: A colonialidade do saber: eurocentrismo e ciências sociais. 1a. ed. Buenos Aires: Consejo Latinoamericano de Ciências Sociales - CLACSO, 2005, p. 08-23. 
LOCKE, John. Segundo Tratado sobre o Governo Civil. Tradução de Magda Lopes e Maria Lobo da Costa. s/d. Editora Vozes.

LÓPEZ GUERRA, Luiz. El sistema europeo de protección de derechos humanos. In: GALINDO, George Rodrigo Bandeira; URUEÑA, René; TORRES PÉREZ, Aida (Coord.). Proteção Multinível dos Direitos Humanos. Red de Direitos Humanos e Educação Superior, 2014, p. 165-186.

MENEZES, Wagner. Tribunais internacionais: jurisdição e competência. São Paulo: Saraiva, 2013.

MERRILLS, J. G. The development of international law by the European Court of Human Rights. Manchester: Manchester University Press, 1990.

MIGNOLO, Walter. La opción descolonial. In: Revista letral. N. 1. 2008, p. 3-22.

. Histórias locais/projetos globais: colonialidade, saberes

subalternos e pensamento liminar. Belo Horizonte: Ed. da Universidade Federal de Minas Gerais, 2003.

Who Speaks for the "Human" in Human Rights? In: BARRETO, José-Manuel. Human Rights from a Third World Perspective: critique, history and international law. Newcastle: Cambridge Scholars Publishing, 2013, p. 4464.

PEREIRA, Gustavo Oliveira de Lima. Bem-vindo ao deserto dos direitos humanos: o 11 de setembro e o choque de fundamentalismos. In: BORGES, Rosa Maria Zaia; AMARAL, Augusto Jobim do; PEREIRA, Gustavo Oliveira de Lima. (Org.) Direitos Humanos e Terrorismo. Porto Alegre: EdiPUCRS, 2014. p. 53-78.

QUIJANO. Colonialidade do poder, eurocentrismo e América Latina. In: LANDER, Edgardo. (Org.). A colonialidade do saber: eurocentrismo e ciências sociais. 1a. ed. Buenos Aires: Consejo Latinoamericano de Ciências Sociales CLACSO, 2005, p. 107-130.

RASILLA DEL MORAL, Ignacio de la. The Increasingly Marginal Appreciation of the Margin of Appreciation Doctrine. p. 611-624. German Law Journal. Vol. 07 No. 06

RIOS, Roger Raupp. Direito da antidiscriminação: discriminação direta, indireta e ações afirmativas. Porto Alegre: Livraria do Advogado, 2008.

SHELTON, Dinah. Prohibición de Discriminación en el Derecho Internaciona de los Derechos Humanos. Anuario de Derechos Humanos. No. 4. Universidad Nacional de Chile, 2008. 
SQUEFF. Tatiana de Almeida Freitas Rodrigues Cardoso. A violação de jus cogens pelo Estado em casos de terrorismo: uma análise do caso Jean Charles de Menezes. Revista de Direitos Humanos em Perspectiva. Brasília. v. 2. n. 1. p. 170-191. Jan/Jun. 2016

TOMUSCHAT, Christian. Human rights: Between Idealism and Realism. $2^{\text {nd }}$ ed. rev. and expanded. New York: Oxford University Press, 2008.

UNITED NATIONS. General Assembly Distr. GENERAL A/RES/53/22. 16 November 1998

VISENTINI, Paulo Fagundes. A vida após a morte: breve história mundial do presente pós- "fim da história”. Tempo. Rio de Janeiro, nº 16, 2004, p. 435-57. 